\title{
The Relationship of Myogenic Temporomandibular Disorders with Depression and Health-Related Quality of Life In Non-Dialysis Chronic Kidney Disease Diyalize Girmeyen Kronik Böbrek Hastalarında Miyojenik Temporomandibular Hastalikların Depresyon ve Sağlıkla İlgili Yaşam Kalitesi ile İlişkisi
}

Fatih YILMAZ, Sevcihan GUNEN YILMAZ, ${ }^{2}$ Hasan SOZEL $^{3}$

${ }^{1}$ Antalya Atatürk State Hospital, Department of Nephrology, Antalya, Turkey

${ }^{2}$ Akdeniz University Faculty of Dentistry, Department of Oral and Maxillofacial Radiology, Antalya, Turkey

${ }^{3}$ Akdeniz University Faculty of Medicine, Department of Internal Medicine, Antalya, Turkey

Yazışma Adresi

Correspondence Address

Hasan SOZEL

Akdeniz University Faculty of Medicine, Department of Internal Medicine, Antalya, Turkey dr07hasan@hotmail.com

Geliș tarihi / Received : Kas 27, 2020 Kabul tarihi / Accepted : Ara 29, 2020 Elektronik yayın tarihi : Eyl 01, 2021 Online published

Bu makalede yapılacak atıf: Cite this article as:

Yilmaz F, Gunen Yilmaz S, Sozel H.

The Relationship Of Myogenic Temporomandibular Disorders With Depression And Health-Related Quality Of Life In Non-Dialysis Chronic Kidney Disease

Akd Med J / 2021; 7(3):407-414

Fatih YILMAZ

ORCID ID: 0000-0003-4599-3299 Sevcihan GUNEN YILMAZ ORCID ID: 0000-0002-4566-2927 Hasan SOZEL

ORCID ID: 0000-0002-9439-1588

\begin{abstract}
Objective

In this study it was aimed to investigate the relationship between myogenic temporomandibular disorders (mTMD) and depression and quality of life in non-dialysis chronic kidney disease (NDCKD).
\end{abstract}

\section{Methods}

This study included 214 with NDCKD patients. The diagnosis of mTMD was based on the Fonseca Anamnestic Index (FAI). Depression was assessed using the Beck Depression Inventory (BDI). Health-related quality of life (HRQOL) was determined using the Short Form-36 (SF-36).

\section{Results}

$40.6 \%$ of 214 patients were diagnosed with mTMD. mTMD prevalence in stage- $3,-4$, and -5 NDCKD patients were $33.6 \%, 46.8 \%$, and $57.1 \%$ respectively. $32.2 \%$ of the patients were diagnosed with depression. The prevalence of depression in NDCKD stage-3, -4 and 5 was $27.8 \%, 32.8 \%$ and $50 \%$, respectively. Depression was detected in $42.5 \%$ of the patients presenting with mTMD and $25.1 \%$ with no TMD ( $\mathrm{p}=0.004)$. mTMD severity was positively associated with the BDI score and C-reactive protein, and negatively with albumin, the Physical Component Summary Score, and Mental Component Summary scores of SF-36. SF-36 score showed a statistically significant negative correlation with FAI and BDI scores $(\mathrm{p}<0.05)$.

\section{Conclusion}

Myogenic TMD is very common among patients with NDCKD patients and is related to depression and HRQOL.

Keywords: Chronic kidney disease, Temporomandibular disorders, Depression, Quality of life

ÖZ

Amaç

Bu çalışmada, diyalize girmeyen kronik böbrek hastalarında (NDCKD) miyojenik temporomandibular hastalıklar (mTMH) ile depresyon ve yaşam kalitesi arasındaki ilişkinin araştırılması amaçlanmıştır.

\section{Metotlar}

Bu çalışma, 214 diyalize girmeyen kronik böbrek hastasını içermekteydi. Miyojenik temporo- 
mandibular hastalık (mTMH) tanısı Fonseca Anamnestic Index'e (FAI) göre konuldu. Depresyon, Beck Depresyon Envanteri (BDI) kullanılarak değerlendirildi. Sağlıkla ilişkili yaşam kalitesi (HRQOL) kısa form-36 (SF-36) kullanılarak belirlendi.

\section{Bulgular}

İkiyüz ondört hastanın \% 40,6'sına miyojenik TMH tanısı konuldu. Evre 3,4 ve 5 NDCKD hastalarında mTMH prevalans1 sirasiyla \% 33,6, \% 46,8 ve \% 57,1 idi. Hastaların \% 32,2 'si depresyon tanıs1 ald1. NDCKD evre 3,4 ve 5 'te depresyon prevalans1 sirasiyla $\% 27,8, \% 32,8$ ve $\% 50$ idi. Depresyon mTMH olan hastaların \% 42,5'inde ve TMH 'si olmayanların \% 25,1'inde saptand 1 ( $\mathrm{p}=0.004)$. mTMH şiddeti, BDI skoru ve C-reaktif protein ile pozitif olarak ve SF-36'nın albümin, Fiziksel Bileşen Özet Skoru ve Mental Bileşen Özet skorları ile negatif olarak ilişkiliydi. SF-36 skoru, FAI ve BDI skorları ile istatistiksel olarak anlamlı negatif bir korelasyon gösterdi $(\mathrm{p}<0.05)$.

\section{Sonuç}

Miyojenik TMH, diyalize girmeyen kronik böbrek hastaları arasında çok yaygındır ve depresyon ve sağlıkla ilgili yaşam kalitesi ile ilişkilidir.

Anahtar sözcülkler: Kronik böbrek hastalığg, Temporomandibular hastalıklar, Depresyon, Yaşam kalitesi

\section{INTRODUGTION}

Temporomandibular disorders (TMDs), affecting joints, muscles, and related structures (1), is a common public health problem that is often accompanied by pain in the jaw movement, limitation of mouth opening, clicking, and crepitation $(2,3)$. The etiology of TMD is multifactorial and psychological factors can also contribute to the etiological causes (4). Several studies have described a high prevalence of psychosocial disorders in patients with TMD (5). TMD may affect health-related quality of life (HRQOL). In previous studies, it was shown that HRQOL was poorer in patients with TMD (6). This study hypothesizes that a similar relationship exists in patient with chronic kidney disease (CKD).

Depression is the most widespread psychiatric illness in CKD cases and it has a multifactorial etiology (anemia, bone-mineral disorders, multiple drug use, erectile dysfunction, restless leg syndrome, anxiety of initiation of dialysis, etc.) (7-9). The prevalence of depression in CKD patients is reported to be between $20-30 \%$ and effective treatment for depression in people with CKD may reduce mortality (9). Although the relationship between TMD and depression is well known, there is only limited data on TMD among CKD patients. A few studies have been reported in the literature in which an oral health evaluation was performed in CKD patients $(10,11)$. However, there is no data on the relationship between myogenic TMD (mTMD), depression, and HRQOL in non-dialysis CKD (NDCKD) patients.

The diagnosis of TMD is often made clinically and radiologically without the need for laboratory parameters. In TMD subtypes, the levels of inflammatory cytokines (interleukin (IL) -1, IL-6, IL-8, tumor necrosis factor (TNF) -alpha) and their receptors, prostaglandin and leukotrienes are increased in the synovial fluid, and these in turn have been shown to cause pain, erosion and degeneration of joint-bone surfaces in temporomandibular joint (TMJ) (12-14). It has been shown that inflammatory cytokines such as IL-6, TNF- $\alpha$, C-reactive protein (CRP) and acute phase reactants are higher in patients with CKD than in patients with normal renal function, and these biomarkers are associated with sarcopenia (15).

This study aimed to determined the relationship between mTMD with biochemical parameters, depression, and HRQOL in NDCKD patients.

\section{MATERIAL and METHOD}

\section{Study population}

The subjects for this cross-sectional and descriptive study were CKD patients admitted to the nephrology polyclinic. The study population selected from patients with stage 3-5 non-dialysis CKD (NDCKD). The estimated glomerular filtration rate (eGFR) was calculated using the CKD Epidemiology Collaboration (CKD-EPI) equation (16). Accordingly, stage 3, 4 and 5 CKD was defined as an eGFR of 60 to 30, 29.9 to 15 and $<15 \mathrm{ml} / \mathrm{min} / 1.73 \mathrm{~m} 2$, respectively. The approval of the local ethics committee was received (Akdeniz University, Faculty of Medicine, Clinical research ethics committee) (70904504/90-27.02.2019). Informed consent was obtained from all patients. The research complied with the Helsinki Declaration.

\section{Sociodemographic variables}

The sociodemographic and clinical characteristics, including age, smoking status, alcohol abuse, marital status, educational level, and economic status were recorded. Diabetes, hypertension, hyperlipidemia, coronary artery disease, previous renal transplantation, etiology of $\mathrm{CKD}$, and medication use were also recorded (Table I-II).

The exclusion criteria were as follows being aged $<18$ or $>80$ years, choosing not to participate, in the study, having a psychiatric or mental illness, using sedatives, hypnotics or steroids, having been diagnosed with head and neck cancer, or having a cardiac or cerebrovascular disease, hypothyroidism, or hyperthyroidism, chronic liver disease, and head and neck trauma. Body mass index (BMI) was calculated $(\mathrm{kg} / \mathrm{m} 2)$ by dividing body weight $(\mathrm{kg})$ by the square of the height (meters $\mathrm{x}$ meters, $\mathrm{m} 2$ ).

To investigate the prevalence of TMD, the Fonseca anamnestic index (FAI) (1994) was used (17). The HRQOL assessment was performed using the Short-Form 36 (SF-36) questionnaire. The diagnosed and severity of depression was determined by administering the Beck Depression Inventory (BDI). 
The Relationship of Myogenic Temporomandibular Disorders with Depression and Health-Related Quality of Life In Non-Dialysis Chronic Kidney Disease

Table I. Baseline demographic and clinical characteristics of patients present and absent temporomandibular disorders

\begin{tabular}{|lccc|}
\hline Parameters & mTMD present & TMD absent & P value \\
\hline Age [years] & $54.7 \pm 15.1$ & $46.8 \pm 12.3$ & 0.01 \\
\hline Gender [M/F] [n] & $26 / 61$ & $69 / 58$ & 0.02 \\
\hline BMI [kg/m/] & $25.2 \pm 4.5$ & $24.8 \pm 4.1$ & 0.18 \\
\hline Smoker/non smoker [n] & $28 / 59$ & $39 / 88$ & 0.22 \\
\hline Diabetes mellitus [present/absent] [n] & $22 / 65$ & $34 / 93$ & 0.34 \\
\hline Hypertension [present/absent] [n] & $34 / 53$ & $46 / 81$ & 0.06 \\
\hline Hyperlipidemia [present/absent] [n] & $19 / 68$ & $29 / 98$ & 0.11 \\
\hline CAD [present/absent] [n] & $8 / 79$ & $15 / 112$ & 0.29 \\
\hline Marital status [mamried/unmamied] [n] & $66 / 21$ & $88 / 39$ & 0.08 \\
\hline Living [aloneppartmer] [n] & $8 / 79$ & $11 / 116$ & 0.37 \\
\hline Place of residence [rural/urban] [n] & $31 / 56$ & $39 / 88$ & 0.05 \\
\hline $\begin{array}{l}\text { Education [illiterate or primary school] } \\
\text { [n,\%] }\end{array}$ & $28,32.1 \%$ & $29,22.8 \%$ & $\mathbf{0 . 0 2}$ \\
\hline Working status [yes/no] [n] & $28 / 59$ & $54 / 73$ & $\mathbf{0 . 0 4}$ \\
\hline
\end{tabular}

Abbreviations: SD, Standard deviation; BMI, Body mass index; CAD, Coronary artery disease; TMD, Temporomandibular disorders; M, Male; F, Female;

\section{Fonseca Anamnestic Index (FAI)}

FAI is a simple, easy-to-use, and low-cost diagnostic tool (17). The FAI score is used to diagnose TMD and evaluates the severity of the disorder $(10,18)$. It has high sensitivity and specificity for mTMD (6). FAI is a functional assessment scale, which contains 10 objective questions which there are three possible answers: "no (0 point)", "sometimes (5 points)", and "yes (10 points)". The total score gives the FAI classification. FAI is evaluated as follows: 70-100 points, severe TMD; 45-65 points, moderate TMD; 20-40 points, mild TMD; and $0-15$ points, TMD-free $(17,18)$. TMD is diagnosed on FAI scores of $\geq 20$. the patients were divided into two groups according to their FAI scores (mTMD and non TMD).

\section{Beck Depression Inventory (BDI)}

BDI-II is a test used to evaluate depression severity consisting of 21 multiple choice questions that have been validated $(19,20)$. In these questions, 0 points represent the absence of a problem while 3 points represent the extreme severity of a problem. Depression is defined based on a BDI score of $>18$. The patients were classified as having normal (BDI, 0-9), mild (BDI, 10-18), moderate (BDI, 19-29), and severe (BDI, 30-63) depression. Higher BDI scores indicate more severe depression. BDI is a valid index of depression, and correlate well with the diagnostic criteria for depression (21). In many studies, the BDI score has been used in CKD patients to evaluate depressive behaviors (22).

\section{Quality of life assessment (QOL)}

The Medical Outcomes Study 36-Item Short Form (SF-36) survey is a generally used generic quality of life tool consisting of eight health domains (physical functioning, general health, social functioning, emotional role, physical role, vitality, pain, mental health) and the summary scores of two components (mental and physical) $(23,24)$. The four subscales of physical function, role of physical limitation due to physical problems, body pain, and general health are included in the physical component summary (PCS) (25). The four subscales of vitality, social function, role of emotional limitation due to emotional problems, and mental health are represented by the mental component summary (MCS) (25). A higher SF-36 scale score indicates better HRQOL. SF-36 is a well-standardized questionnaire for evaluating HRQOL and has been verified for use in patients with CKD (26). This study used the SF-36 version that was adapted to the Turkish population (23).

\section{Laboratory assessment}

Venous blood samples were collected from all the patients after $12 \mathrm{~h}$ of fasting. All laboratory tests were performed by the hospital's central laboratory, with an auto-analyzer used to determine biochemical data. Parameters were fasting blood glucose, urea, creatinine, albumin, sodium, potassium, calcium, phosphorus, hemoglobin, and parathyroid hormone. Hemogram was obtained using the automated blood counting device. The intact parathyroid hormone value was measured by the electrochemiluminescence immunoassay (Roche PTH (Intact PTH)). The albumin level was measured by the bromocresol green method and the serum CRP level by rate nephelometry (normal range:0-0.5 mg/dL).

\section{Statistical analyses}

Statistical analysis was performed using SPSS software ver. 17.0 (SPSS, Chicago, IL, USA). The normality of the data was tested using the Kolmogorov-Smirnov test. The data was shown as mean \pm standard deviation or median (IQR) values where appropriate. Statistical analysis was performed by Student's t-test for parametric variables, the Mann-Whitney $\mathrm{U}$ test for nonparametric variables. The $\chi 2$-test was performed for qualitative variables in the comparisons between the two groups. The parameters affecting FAI and BDI scores were investigated using Spearman/Pearson correlation where appropriate. A p-value of $<0.05$ was considered to be significant in the all statistical tests.

\section{RESULTS}

The study population consisted of 214 stage 3-5 NDCKD patients with a mean age of 43.6 (range, 24-66) years. The disease stage distribution of the 214 CKD patients was as follows: stage-3 in $57 \%(n=122)$, stage-4 in $29.9 \%(n=64)$, and stage- 5 in $13.1 \%(n=28)$. The etiology of CKD was diabetes in $30.8 \%(n=66)$, hypertension in $17.7 \%(n=38)$, nephrolithiasis in $7.9 \%(n=17)$, polycystic kidney disease in $6 \%$ $(n=13)$, glomerulonephritis in 6.5\% $(n=14)$, vesicoureteral reflux in $3.2 \%(n=7)$, familial mediterranean fever in $4.2 \%$ $(n=9)$, secondary amyloidosis in $2.3 \%(n=5)$, interstitial nephritis in $1.8 \%(\mathrm{n}=4)$, Alport syndrome in $0.9 \%$ ( 2 patients), and unclear in $18.2 \%(\mathrm{n}=39)$.

The demographic, clinical characteristics, and laboratory measurements are presented in detail in Tables I and II. For the sociodemographic factors, significant differences were 
observed between the MTMD and non TMD groups in terms of age $(p=0.01)$, gender $(p=0.02)$, working status $(p=0.04)$, and education $(\mathrm{p}=0.02)$.

However no statistically significant difference was found between the mTMD and non TMD groups in terms of FBG, urea, creatinine, e-GFR, alkaline phosphatase, calcium and phosphorus measurements $(\mathrm{p}>0.05)$ (Table II). In patients with TMD the $\mathrm{iPTH}(\mathrm{p}=0.03)$, CRP $(\mathrm{p}=0.01)$ and ferritin $(p=0.02)$ levels were significantly higher, and the albumin $(\mathrm{p}=0.02)$ and hemoglobin levels $(\mathrm{p}=0.04)$ were significantly lower (Table II). The FAI scores of all CKD groups are presented in Table II.

Table I. Comparison of clinical and laboratory parameters of groups

\begin{tabular}{|c|c|c|c|}
\hline Parameters & TMD present & TMD absent & p value \\
\hline Glucose [mg/dI] & $98.3 \pm 26.1$ & $95.8 \pm 23.6$ & 0.36 \\
\hline BUN [mg/dL] & $41.2 \pm 13.6$ & $43.7 \pm 12.2$ & 0.26 \\
\hline Creatinine [mg/Ll] & $3.2 \pm 1.3$ & $3.3 \pm 1.1$ & 0.12 \\
\hline GFR [m/ $\left[\mathrm{min} / 1.73 \mathrm{~m}^{2}\right]$ & $29.6 \pm 11.3$ & $28.7 \pm 12.4$ & 0.09 \\
\hline CRP [mgL] [median] [25-75\%] & $2.6[1.6-9.3]$ & $1.8[0.6-4.3]$ & 0.01 \\
\hline Albumin [gdL] & $3.5 \pm 1.2$ & $3.8 \pm 1.3$ & 0.02 \\
\hline Calcium [mg/dI] & $8.4 \pm 2.6$ & $8.8 \pm 2.5$ & 0.14 \\
\hline Phosphorus [mg/dL] & $4.4 \pm 2.3$ & $4.8 \pm 2.1$ & 0.19 \\
\hline Intact PTH $[\mathrm{gg} / \mathrm{L}][\% 25-75]$ & $213.1[47.2-384.4]$ & $127.4[57.0-213.4]$ & 0.03 \\
\hline $\begin{array}{l}\text { ALP [U/L] [median] [25-75\%] } \\
\text { Hemoglobin [g/dL] }\end{array}$ & $94.4[633.2-145.8]$ & $106.2[83.2-185.8]$ & 0.11 \\
\hline Hemoglobin [g/dI] & $11.1 \pm 3.7$ & $11.7 \pm 3.4$ & 0.04 \\
\hline Fernitin $[\mathrm{mg} / \mathrm{L}][$ mediam] $[25-75 \%]$ & $191.7[126.7-384.2]$ & $101.8[96.4-289.2]$ & 0.02 \\
\hline Spot PCR [mg/mg] & $1.44 \pm 0.25$ & $1.58 \pm 0.33$ & 0.18 \\
\hline \begin{tabular}{|l} 
FAI scores \\
CKD stage-3
\end{tabular} & $25.5 \pm 5$ & $10.5 \pm 2.0$ & 0.03 \\
\hline CKD stage -4 & $32.5 \pm 10.5$ & $12.5 \pm 4.5$ & 0.03 \\
\hline CKD stage- 5 & $47.5 \pm 12.5$ & $15.5 \pm 6.0$ & 0.02 \\
\hline All patients & $32.5 \pm 6.5$ & $12.0 \pm 4.5$ & 0.01 \\
\hline \multicolumn{4}{|l|}{ Treatment } \\
\hline nsulin [n \%] & $14,16.1 \%$ & $22,17.3 \%$ & 0.36 \\
\hline $\mathrm{DAD}[\mathrm{n}, \%]$ & $17,19.5 \%$ & $28,220 \%$ & 0.28 \\
\hline ESA [n, \%] & $24,27.5 \%$ & $32,25.1 \%$ & 0.24 \\
\hline \multicolumn{4}{|l|}{ Anti-hypertensive $[\mathrm{n} \%]$} \\
\hline ACEI & $21,24.1 \%$ & $38,29.9 \%$ & 0.08 \\
\hline ARB & $14,16.1 \%$ & $19,14.9 \%$ & 0.06 \\
\hline $\mathrm{CCB}$ & $17,19.5 \%$ & $28,22.0 \%$ & 0.10 \\
\hline$-8 \mathrm{~B}$ & $11,12.6 \%$ & $21,16.5 \%$ & 0.13 \\
\hline$-\mathrm{BB}$ & $9.10 .3 \%$ & $15,11.8 \%$ & 0.22 \\
\hline Vitamin D abalogue [n $\%$ ] & $26,29.8 \%$ & $35,27.5 \%$ & 0.19 \\
\hline CBPB [n \%] & $25,28.7 \%$ & $37.29 .1 \%$ & 0.28 \\
\hline Statin [n \% & $22,25.2 \%$ & $31,24.4 \%$ & 0.26 \\
\hline ASA [n] & $15,17.2 \%$ & $23,18.1 \%$ & 0.13 \\
\hline
\end{tabular}

Abbreviations: ALP, Alkaline phosphatase; PCR, Protein creatinine ratio; PTH, Parathyroid hormone; GFR, Glomerular filtration rate; CRP, C-reactive protein; ESA, Erythropoiesis stimulating agent; CBPB, Calcium-based phosphate binders; CCB, Calcium channel blocker; $\alpha \mathrm{B}$, Alpha-blocker; ARB, Angiotensin II receptor blocker; $\beta \mathrm{B}$, Beta-blocker; $\mathrm{ACEI}$, Angiotensin-converting enzyme inhibitors; ASA, Acetylsalicylic acid; OAD, Oral antidiabetic; TMD, Temporomandibular disorders; CKD, Chronic kidney disease; FAI, Fonseca anamnestic index

Of the 214 patients, $40.6 \%(n=87)$ were diagnosed with mTMD. The severity of mTMD was mild in $21.9 \%(n=47)$, moderate in $12.6 \%(n=27)$ and severe in $6.1 \%(n=13)$. Of the 87 patients TMD present, $47.1 \%$ were stage- $3(n=41), 34.4 \%$ were stage-4 $(n=30)$ and $18.5 \%$ were stage-5 NDCKD $(n=16)$. mTMD prevalence in stage-3, -4 , and -5 NDCKD patients were $33.6 \%, 46.8 \%$, and $57.1 \%$ respectively. The frequency of mTMD was higher in stage-4 and 5 NDCKD cases than in stage-3 $(p<0.05)$, but there was no significant difference between stage- 4 and $5(\mathrm{p}=0.17)$. The prevalence of $\mathrm{mTMD}$ for NDCKD stage 3-4 and 5 and all patients is shown in Fig.1.

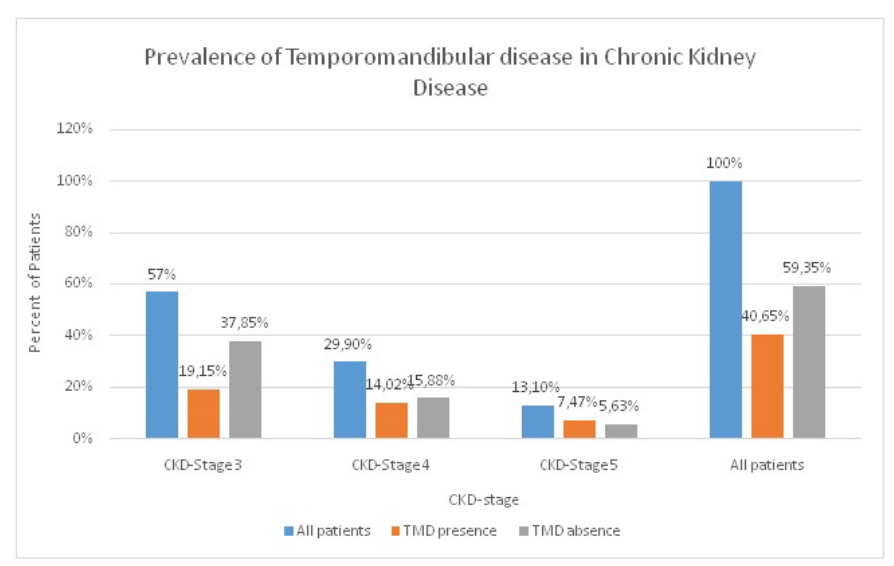

The percentage of patients with depression (BDI scores $>18$, moderate and severe) was $32.2 \%(n=69) .49,3 \%(n=34)$ of these patients had stage-3, 30.4\% ( $\mathrm{n}=21)$ had stage- 4 , and $20.3 \%(n=14)$ had stage-5 NDCKD. The prevalence of depression in NDCKD stage-3, -4 and 5 was $27.8 \%, 32.8 \%$ and $50 \%$, respectively. The difference was not significant in terms of the frequency of depression in stage 3-4 NDCKD, but the frequency of depression in stage 5 was higher than stage 3-4 NDCKD $(\mathrm{p}<0.05)$. Depression was detected in $42.5 \%(n=37)$ of the patients with mTMD and $25.1 \%(n=32)$ of those non TMD $(\mathrm{p}=0.004)$. The prevalence of depression according to CKD stages are shown in Fig.2.

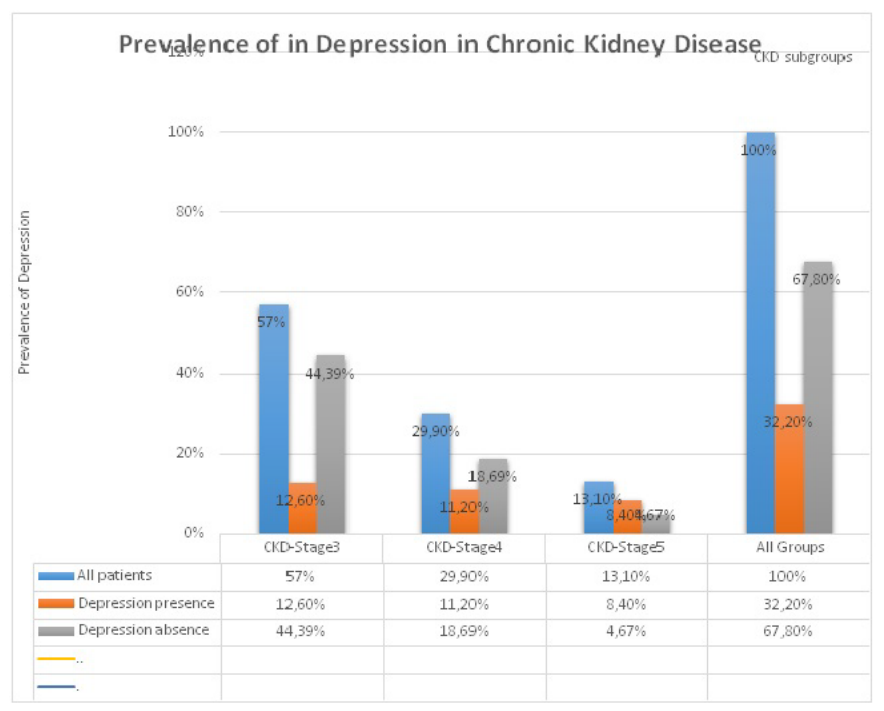


The Relationship of Myogenic Temporomandibular Disorders with Depression and Health-Related Quality of Life In Non-Dialysis Chronic Kidney Disease

The comparisons of the mTMD and non TMD groups in terms of the BDI and SF-36 scores is shown in Table III. The differences between the mean values of the groups BDI score $(p=0.01), \operatorname{PCSS}(p=0.01)$ and $\operatorname{MCSS}(p=0.02)$ were statistically significant.

Table III Results of Beck Depression Inventory Scores and SF-36 among patients present and absent temporomandibular disorders

\begin{tabular}{|lccc|}
\hline Parameters & mTMD present & TMD absent & p value \\
\hline BDIS & $37.2 \pm 10.5$ & $24.9 \pm 9.7$ & $\mathbf{0 . 0 1}$ \\
\hline PF & $64.9 \pm 11.7$ & $66.4 \pm 16.2$ & 0.31 \\
\hline RPL [median] [25-75\%] & $58[0-68.5]$ & $60[25-90]$ & 0.14 \\
\hline Bodily Pain & $42.2 \pm 13.4$ & $48.9 \pm 11.7$ & $\mathbf{0 . 0 3}$ \\
\hline Vitality & $45.8 \pm 10.4$ & $46.2 \pm 13.7$ & 0.22 \\
\hline GHP & $61.6 \pm 14.3$ & $66.2 \pm 12.4$ & $\mathbf{0 . 0 1}$ \\
\hline SF [median] [25-75\%] & $54.5[37.5-65.0]$ & $57.5[45-67.5]$ & $\mathbf{0 . 0 4}$ \\
\hline Mental Health & $62.7 \pm 12.4$ & $63.9 \pm 13.9$ & $\mathbf{0 . 0 2}$ \\
\hline Role Emotional [median] [25-75\%] & $42.4[0-62.6]$ & $64.5[0-100]$ & 0.16 \\
\hline $\begin{array}{l}\text { PCSS } \\
\text { MCSS }\end{array}$ & $37.2 \pm 12.6$ & $\mathbf{0 . 0 1}$ \\
\hline $\begin{array}{l}\text { Abbreviations: PCSS, Physical Component Summary Score; MCSS, Mental Component Summary Score; } \\
\text { RPL, Role-Physical Limitation; PF, Physical Functioning; GHP, General Health Perception; SF, Social }\end{array}$ \\
$\begin{array}{l}\text { Functioning, mTMD, myogenic Temporomandibular disorders, SF-36, Short Form-36, BDIS, Beck Depression } \\
\text { Inventory Score }\end{array}$
\end{tabular}

The correlation analysis of clinical and biochemical parameters with FAI and BDI scores is shown in Table IV. SF-36 score showed a statistically significant negative correlation with FAI and BDI scores $(\mathrm{p}<0.05)$. In addition, the BDI score was positively correlated with the FAI score $(\mathrm{p}=0.01)$.

Table IV Correlations of various parameters of FAl scores and BDI scores

\begin{tabular}{|c|c|c|c|c|}
\hline \multirow[t]{2}{*}{ Parameters } & \multicolumn{2}{|c|}{ FAI Scores } & \multicolumn{2}{|l|}{ BDI scores } \\
\hline & $\mathrm{r}$ & $\mathrm{p}$ & $\mathrm{r}$ & $\mathrm{p}$ \\
\hline Age & 0.245 & 0.01 & 0.285 & 0.01 \\
\hline Gender (Female) & 0.329 & 0.01 & 0.326 & 0.01 \\
\hline BUN & 0.318 & 0.03 & & \\
\hline Creatinine & 0.247 & 0.03 & 0.147 & 0.02 \\
\hline eGFR & -0.347 & 0.01 & -0.325 & 0.02 \\
\hline CRP & 0.414 & 0.02 & 0.257 & 0.02 \\
\hline Albumin & -0.182 & 0.01 & -0.399 & 0.01 \\
\hline $\mathrm{PPTH}$ & 0.241 & 0.02 & & \\
\hline Hemoglobin & -0.265 & 0.13 & -0.342 & 0.04 \\
\hline BDI scores & 0.293 & 0.01 & & \\
\hline SF-36 & -0.317 & 0.04 & -0.382 & 0.03 \\
\hline
\end{tabular}

Abbreviations: CRP, C-reactive protein; iPTH, intact parathyroid hormone; BDI, Beck Depression Inventory, FAI, Fonseca anamnestic index, BUN, blood urea nitrogen; eGFR, estimated glomerular filtration rate;

\section{DISGUSSION}

In this study, in patients NDCKD, the specific relationship between mTMD with depression and HRQOL was evaluated. The results showed a positive relationship between depression and $\mathrm{mTMD}$ in this patient group. It was also demonstrated that the SF-36 scores were lower in NDCKD patients with mTMD compared to those without TMD. In patients with mTMD, HRQOL was lower, and the BDI scores were higher in the advanced CKD stage. The BDI score showed a positive correlation with serum CRP, but a negative correlation with the albumin value and eGFR, while mTMD, BDI score, and CRP were independently and positively correlated, albumin and HRQOL were independently and negatively correlated. This is the first study to evaluate the prevalence of mTMD in NDCKD patients. FAI is suitable for making a mTMD diagnosis and determining its severity (27). Its advantages are that it does not require expertise, it is economical and it is an easy-to-apply questionnaire form that can be answered by any individual who can perceive the questions. However, it cannot replace the DC-TMD algorithm used in TMD diagnosis and classification and made by an experienced specialist. In current study, FAI was used to determine the severity of mTMD. Mild and moderate mTMD was observed more frequently in NDCKD patients, according to FAI. Depression plays a direct causal role in poor HRQOL. CKD is associated with high prevalence of depression, which increases inversely with eGFR (27). TMD and depression are closely related. Several studies have shown that a high prevalence of depression in TMD patients $(21.4 \%-60.1 \%)$ and depression is considered an important risk factor for TMD $(4,5)$. Similarly, patients with depression, present with high prevalence of TMD. Treatment of TMD can reduce depressive behavior and improve QoL. The findings of this study are similar to those of studies conducted in the general population indicating an increased frequency of depression among patients with TMD (4-6).

In this study, the MCSS and PCSS were lower in patients with mTMD. TMD is not potentially life-threatening disorder, but have chronic features that can have an impact on HRQOL. Similarly, CKD can place numerous limitations on a patient's daily life. Depression and low QoL may be seen in CKD patients due to various clinical conditions, such as uremic encephalopathy, pruritus, cerebrovascular diseases, bone-mineral disorders, malnutrition, anemia, hypertension/hypotension, diabetes and extremity loss, as well as socioeconomic and psychological reasons. Furthermore, an increase in medicatons use and essential life changes, such as salt and dietary restrictions may lead to an increased frequency of depression and low QoL.

In this study, when the education status, one of the main factors affecting the QoL and depression of the individual, was examined, high TMD rates were observed in uneducated or primary school graduates and unemployed patients. Al-Jabi SW et al.'s study on hemodialysis patients also found that low education level and unemployment increased the frequency of depression (28).

In this study, it was observed that the frequency of mTMD increased with advanced age in adult NDCKD patients. In the literature, there are studies with different results evaluating age and the frequency of TMD. In the study of Nilsson IM et al., the frequency of TMD in adolescents was higher than in adults (29). In the study of Cui C. et al. age was shown to be a risk factor for TMD (30). Advanced age has been considered as a risk factor for depression in the study of Al-Jabi SW et al. with hemodialysis patients (28). This suggests that advanced age may be a risk factor for mTMD. 
The majority of CKD patients suffer from a varying range of widespread musculoskeletal discomforts. In particular, chronic body pain reduces the QoL and induces the onset of depressive behaviors in patients with CKD (31). TMJ pain may be a component of chronic body pain and may trigger depression. Additionally, in TMD, bruxism, clicking and decreased mouth opening, headache, ear and jaw pain and eating disorders may negatively affect the QoL.

In the current study, PTH levels were significantly higher in patients present mTMD than those absent TMD. This may be related to the presence and severity of secondary hyperparathyroidism. Increased serum phosphorus and FGF-23 levels combined with decreased eGFR from the early stages of CKD stimulate PTH secretion. 25-hydroxyvitamin D deficiency, which is frequently encountered in CKD patients, may also cause TMD. In a study by Shen et al., it showed that osteoarthritis caused by 1.25 -dihydroxyvitamin D deficiency is the cause of TMD by increasing inflammatory cytokine production (32). It was observed that radiological changes in TMJ and teeth loss were correlated with $25(\mathrm{OH}) \mathrm{D}$ levels in patients whose bone mineral density was measured (33). 25(OH)D level was not evaluated in the current study. However, as in the general population, $25(\mathrm{OH}) \mathrm{D}$ deficiency in the CKD population has very high prevalence. Low 25(OH)D levels may explain the destruction of the TMJ (33). In the current study, there was no significant difference between the mTMD and non TMD groups in terms of the use of Ca-containing phosphorus binders and calcitriol. This situation suggests that mTMD which develops in the course of CKD is not only related to vitamin D deficiency.

In many NDCKD patients, reduced appetite and increased inflammation become more apparent with decreasing eGFR. TMD patients frequently experience impaired food intake ability (34). TMD are often associated with eating disorders and anorexia (35), which can exacerbate hypoalbuminemia. This study showed a negative association between serum albumin levels and mTMD severity. In addition, it was observed that the serum albumin levels and depression severity were negatively correlated and SF-36 was positively correlated with serum albumin levels. Previous studies have revealed a correlation between albumin levels and depression. The CRP and ferritin levels were also significantly higher in the mTMD group compared to the non TMD group. In some rheumatologic diseases (systemic lupus erythematosus, rheumatoid arthritis, psoriatic arthritis, and juvenile arthritis), TMJ arthritis may be seen but not expected to affect the joints as a primary allergic disease (36), polycystic ovary syndrome (3), obesity (37) in cases such as low-grade chronic inflammation may be caused TMD. It has been shown that the levels of inflammatory cytokines (interleukin-1, interleukin-6, interleukin-8, and tumor necrosis factor-alpha) increase in the synovial fluid of TMD patients (12).

In this current study, $70.1 \%$ of the patients with mTMD were female, and gender had a significant association with mTMD, as also shown previously $(\mathrm{p}=0.02)$. Similarly in most of the previous population studies, TMD was significantly more common in the female gender $(1,37)$.
This study has certain limitations. Firstly, due to its cross-sectional design, the findings do not prove a cause-effect relationship. However, imprecise interpretation and diagnosis in cross-sectional studies are known to be fairly evenly distributed; therefore, the results are still significant (38). Secondly, this study was performed in a single nephrology clinic. Therefore, the results do not represent all CKD patients. Thirdly, patients with depression using antidepressants were excluded in this study. The purpose of this exclusion is the idea that the possible effects of treated depression on mTMD may be diminished. Fourthly, the presence and/or severity of depression and mTMD was categorized using the BDI and FAI scores, respectively. These scoring systems provide subjective and semi-quantitative measurements. There may have been misclassifications due to a lack of clinical evaluation. However, laboratory tests and radiological evaluations are not undertaken in the first step in the diagnosis of mTMD. The strength is this study is that it was the first to investigate mTMD in NDCKD patients and explore its relationship with depression and QoL in this patient group.

\section{GONGLUSION}

In conclusion, mTMD was associated with a high prevalence of depression and low HRQOL in stage 3-5 NDCKD patients. mTMD may be a cause of high depression prevalence in NDCKD patients. Clinicians need to consider mTMD in depressed CKD patients. Further clinical studies are required to verify the association between depression and mTMD.

Ethics Committee Approval: This research complies with all the relevant national regulations, institutional policies and is in accordance the tenets of the Helsinki Declaration, and has been approved by the Medical Faculty Ethical Committee, Akdeniz University (approval number: 70904504/90-27.02.2019).

Informed Consent: All the participants' rights were protected and written informed consents were obtained before the procedures according to the Helsinki Declaration.

Author Contributions: Concept-F.Y., S.G.Y.; Design F.Y., S.G.Y.; Supervision - F.Y., S.G.Y., H.S.; Resources F.Y., S.G.Y., H.S.; Materials - F.Y., H.S.; Data Collection and/or Processing - F.Y., S.G.Y., H.S.; Analysis and/ or Interpretation - F.Y., S.G.Y., H.S.; Literature Search - S.G.Y., H.S.; Writing Manuscript - F.Y.; Critical Review - F.Y., H.S.

Conflicts of Interest: The authors declare that they have no conflicts of interest.

Financial Disclosure: No financial disclosure was declared by the authors. 
The Relationship of Myogenic Temporomandibular Disorders with Depression and Health-Related Quality of Life In Non-Dialysis Chronic Kidney Disease

\section{REFERENGES}

1. Adern B, Stenvinkel C, Sahlqvist L, Tegelberg A. Preva lence of temporomandibular dysfunction and pain in adult general practice patients. Acta Odontol Scandin. 2014; 72: 585-590.

2. Borahan MO, Mayil M, Pekiner FN. Using cone beam computed tomography to examine the prevalence of condylar bony changes in a Turkish subpopulation. Niger J Clin Pract. 2016;19(2):259-266.

3. Soydan SS, Deniz K, Uckan S, Unal AD, Tutuncu NB. Is the incidence of temporomandibular disorder increased in polycystic ovary syndrome? Br J Oral Maxillofac Surg 2014;52(9):822-826.

4. Selaimen CM, Jeronymo JC, Brilhante DP, Grossi ML. Sleep and depression as risk indicators for temporoman dibular disorders in a cross-cultural perspective: a case-control study. Int J Prosthodont. 2006;19(2):154-161.

5. De La Torre Canales G, Câmara-Souza MB, Muñoz Lora VRM, Guarda-Nardini L, Conti PCR, Rodrigues Garcia RM, Del Bel Cury AA, Manfredini D. Prevalence of psychosocial impairment in temporomandibular disorder patients: A systematic review. J Oral Rehabil. 2018;45(11):881-889. doi: 10.1111/joor.12685. Epub 2018 Jul 17.

6. Natu VP, Yap AU, Su MH, Irfan Ali NM, Ansari A. Temporomandibular disorder symptoms and their associ ation with quality of life, emotional states and sleep quality in South-East Asian youths. J Oral Rehabil. 2018;45(10):756-763.

7. Katon WJ. Epidemiology and treatment of depression in patients with chronic medical illness. Dialog Clin Neuro sci 2011;13: 7-23.

8. Ahrens T, Deuschle M, Krumm B, van der Pompe G, den Boer JA, Lederbogen F. Pituitary-adrenal and sympathet ic nervous system responses to stress in women remitted from recurrent major depression. Psychosom Med. 2008;70(4):461-467.

9. Palmer SC, Vecchio M, Craig JC, Tonelli M, Johnson DW, Nicolucci A, Pellegrini F, Saglimbene V, Logrosci no G, Hedayati SS, Strippoli GF. Association between depression and death in people with CKD: a meta-analy sis of cohort studies. Am J Kidney Dis.

2013;62(3):493-505. doi: 10.1053/j.ajkd.2013.02.369.

10. Cunha FL, Tagliaferro EP, Pereira AC, Meneghim MC, Hebling E. Oral health of a Brazilian population on renal dialysis. Spec Care Dentist. 2007;27(6):227-231.

11. Bots CP, Poorterman JH, Brand HS, Kalsbeek H, van Amerongen BM, Veerman EC, Nieuw Amerongen AV. The oral health status of dentate patients with chronic renal failure undergoing dialysis therapy. Oral Dis. 2006 Mar;12(2):176-80. doi: 10.1111/j.1601-0825.2005.01183.x.

12. Takahashi T, Kondoh T, Fukuda M, Yamazaki Y, Toyosa ki T, Suzuki R. Proinflammatory cytokines detectable in synovial fluids from patients with temporomandibular disorders. Oral Surg Oral Med Oral Pathol Oral Radiol Endod 1998;85(2):135-141.

13. Suvinen TI, Reade PC. Temporomandibular disorders: a critical review of the nature of pain and its assessment. J Orofac Pain. 1995;9(4):317-339.

14. Kostrzewa-Janicka J, Jurkowski P, Nedzi-Gora M, Mier zwinska-Nastalska E. "Inflammatory markers in temporomandibular joint disorders. Cent Eur J Immunol. 2012; 37(3):290-293.

15. Souza VA, Oliveira D, Barbosa SR, Corrêa JODA, Colugnati FAB, Mansur HN, Fernandes NMDS, Bastos MG. Sarcopenia in patients with chronic kidney disease not yet on dialysis: Analysis of the prevalence and associated factors. PLoS One. 2017; 27;12(4):e0176230. doi: 10.1371/journal.pone.0176230.

16. Levey AS, Stevens LA, Schmid CH, Zhang YL, Castro AF 3rd, Feldman HI, Kusek JW, Eggers P, Van Lente F, Greene T, Coresh J; CKD-EPI (Chronic Kidney Disease Epidemiology Collaboration). A new equation to estimate glomerular filtration rate. Ann Intern Med. 2009 May 5;150(9):604-12. doi:

10.7326/0003-4819-150-9-200905050-00006.

17. Fonseca DM, Bonfante G, Valle AL, De Freitas SFT. [Diagnóstico pela anamnese da disfunção craniomandib ular] Rev Gaucha Odontol. 1994;4(1):23-32.

18. Bevilaqua-Grossi D, Chaves TC, de Oliveira AS, Monteiro-Pedro V. Anamnestic index severity and signs and symptoms of TMD. Cranio. 2006;24(2):112-118.

19. Hedayati SS, Bosworth HB, Kuchibhatla M, Kimmel PL, Szczech LA. The predictive value of self-report scales compared with physician diagnosis of depres sion in hemodialysis patients. Kidney Int 2006; 69:1662-1668.

20. Hedayati SS, Finkelstein FO. Epidemiology, diagnosis, and management of depression in patients with CKD. Am J Kidney Dis 2009; 54: 741-752.

21. Afsar B, Elsurer R, Yilmaz MI, Eyileten T, Yenicesu M. Irritable bowel syndrome in haemodialysis: Prevalence, link with quality of life and depression. Nephrology (Carlton). 2010;15(2):197-202.

22. Han Y, Song X, Liu Y, Zhang W, Li J, Tu Y, Chang W. The effects of depression and age on sleep disturbances in patients with non-dialysis stage 3-5 chronic kidney disease: a single-center study. Int Urol Nephrol. 2020;52(4):739-748. doi: 10.1007/s11255-020-02416-y. Epub 2020 Mar 2.

23. Ware JE, Jr, Sherbourne CD. The MOS 36-Item short-form health survey (SF-36) I: Conceptual frame work and item selection. Med Care 1992;30:473-483.

24. Ware JE, Jr. SF-36 health survey update. Spine. 2000;25(24):3130-3139.

25. Sung SA, Hyun YY, Lee KB, Park HC, Chung W, Kim YH, Kim YS, Park SK, Oh KH, Ahn C; KNOW-CKD Study Investigators. Sleep Duration and Health-Related Quality of Life in Predialysis CKD. Clin J Am Soc Nephrol. 2018;7;13(6):858-865. doi: 10.2215/C 
JN.11351017. Epub 2018 May 3.

26. Brown SA, Tyrer F, Clarke AL, Lloyd-Davies LH, Niyi-Odumosu FA, Nah RGQ, Stein AG, Tarrant C, Smith AC. Kidney symptom questionnaire: Develop ment, content validation and relationship with quality of life. J Ren Care. 2018;24. doi: 10.1111/jorc.12247.

27. Berni KC, Dibai-Filho AV, Rodrigues-Bigaton D. Accu racy of the Fonseca anamnestic index in the identifica tion of myogenous temporomandibular disorder in female community cases. J Bodyw Mov Ther. 2015;19(3):404-409.

28. Al-Jabi SW, Sous A, Jorf F, Taqatqa M, Allan M, Sawal ha L, Lubadeh E, Zyoud SH, Sweileh WM. Depression in patients treated with haemodialysis: a cross-sectional study. Lancet. 2018;21;391 Suppl 2:S41. doi: 10.1016/S0140-6736(18)30407-0. Epub 2018 Feb 21.

29. Nilsson IM, List T, Drangsholt M. Prevalence of temporomandibular pain and subsequent dental treatment in Swedish adolescents. J Orofac Pain 2005;19:144-50.

30. Cui C, Zheng L, Fan Y, Zhang J, Xu R, Xie J, Zhou X. Parathyroid hormone ameliorates temporomandibular joint osteoarthritic-like changes related to age. Cell Prolif. 2020;53(4):e12755. doi: 10.1111/cpr.12755. Epub 2020 Mar 10.

31. Teles F, Amorim de Albuquerque AL, Freitas Guedes Lins IK, Carvalho Medrado P, Falcão Pedrosa Costa A. Quality of life and depression in haemodialysis patients. Send to Psychol Health Med. 2018;23(9):1069-1078.
32. Shen $\mathrm{M}$, Luo $\mathrm{Y}$, Niu $\mathrm{Y}$, et al. 1,25(OH)2D deficiency induces temporomandibular joint osteoarthritis via secre tion of senescence-associated inflammatory cytokines. Bone. 2013;55(2):400-409.

33. Jagur O, Kull M, Leibur E, Kallikorm R, Loorits D, Lember M, Voog-Oras U. Relationship between radio graphic changes in the temporomandibular joint and bone mineral density: a population based study. Stomatologija. 2011;13(2):42-8.

34. Haketa T, Kino K, Sugisaki M, Amemori Y, Ishikawa T, Shibuya T, Sato F, Yoshida N. Difficulty of food intake in patients with temporomandibular disorders. Int J Prost hodont. 2006;19(3):266-70.

35. Romanos GE, Javed F, Romanos EB, Williams RC. Oro-facial manifestations in patients with eating disorders. Appetite. 2012;59(2):499-504.

36. Nishioka M, Ioi H, Matsumoto R, Goto TK, Nakata S, Nakasima A, Counts AL, Davidovitch Z. TMJ osteoar thritis/osteoarthrosis and immune system factors in a Japanese sample. Angle Orthod. 2008;78(5):793-8. doi: 10.2319/091407-438.

37. Jordani PC, Campi LB, Circeli GZ, Visscher CM, Bigal $\mathrm{ME}$, Gonçalves DA. Obesity as a risk factor for temporo mandibular disorders. J Oral Rehabil. 2017;44(1):1-8.

38. Altman DG. Practical statistics for medical research. 1. London, UK: Chapman \& Hall; 1991. 